\title{
Comparative determination of physical stress and strain on milkers in milking parlours on dairy farms in Upper Austria, using ECG, an activity sensor and spirometer
}

\author{
Elisabeth Quendler ${ }^{1}$, Magdalena Mayrhofer ${ }^{1}$, Bernhard Prinz ${ }^{2}$, Alfred Nimmerichter ${ }^{2}$ \\ ${ }^{1}$ Department of Sustainable Agricultural Systems, Division of Agricultural Engineering, University of Natural Resources \\ and Life Sciences, Vienna, Austria \\ ${ }^{2}$ University of Applied Sciences Wiener Neustadt, Sport and Exercise Sciences, Wiener Neustadt, Austria
}

Quendler E, Mayrhofer M, Prinz B, Nimmerichter A. Comparative determination of physical stress and strain on milkers in milking parlours on dairy farms in Upper Austria, using ECG, an activity sensor and spirometer. Ann Agric Environ Med. 2017; 24(2): $294-298$.

\begin{abstract}
To-date, the impact of modern milking parlors in dairy farming on physical strain has not been the subject of many studies. Therefore, this case study aims to record and evaluate the physical strain during the entire milking process, including the oxygen consumption $\left(\mathrm{VO}_{2}\right)$, heart rate $(\mathrm{HR})$ and metabolic rate $(\mathrm{WkJ}$, Watt) of milkers. The recording was conducted with a portable respiratory gas analysis system and an ECG and activity sensor on 4 dairy farms in Austria. Eight subjects aged from 45-52 years, with a mean age 50 \pm 2.4 SD, participated and the data were recorded during the milking process in 2 types of milking parlours. For assessment, the entire milking process was divided into preparation, milking and follow-up work. The entire milking process was performed with an average oxygen consumption of $46.5 \mathrm{l} / \mathrm{h}$ and a heart rate of $98 \mathrm{bpm}$, which is below the anaerobic threshold; whereas in the preparation and follow-up work, this threshold was exceeded. Generally, during the milking process, a moderate physical strain (32.4\%) and a balanced metabolic rate ( 143 watt $\left./ \mathrm{m}^{2}\right)$ were determined. The physical strain in female milkers was $9.2 \%$ higher than in male milkers throughout the entire process. Reduction of physical strain can be achieved through additional breaks, reduced work speed, division of labour and technical devices.
\end{abstract}

\section{Key words}

physical strain, milking parlor, heart rate, oxygen consumption

\section{INTRODUCTION}

Dairy farming is characterized not only by a heavy workload but also by a high proportion of recurrent and time-bound work [1]. The dairy industry and cattle husbandry are the most important branches of Austrian agriculture. In 2014, 534,041 dairy cows produced 3,493,861 liters of raw milk [2]. With the decline in tie-stalls and the introduction of free stall barns in the dairy sector, the corresponding bucket and pipeline milking changed to modern milking systems that are regarded as placing less physical strain on humans [3]. In the free stall barn, there is a distinction between the individual animal and the group milking parlour. Group milking parlours include the following types: herring bone, side-by-side, swing-over, and milking carousel.

According to Auernhammer (1989), work strain results from physical and mental activity influenced by the workplace and the working environment [4]. Hence, the strain may vary depending on technical equipment and design of the workplace [5]. Parameters such as gender-specific height and weight, as well as shoulder height and arm's length, have an impact on the strain of the milker experiences [6]. The optimal working area is important in connection with musculoskeletal disorders.

During milking, the wrists, elbow region, shoulder region and upper back are particularly stressed [7]. Because of the

Address for correspondence: Elisabeth Quendler, University of Life Sciences and Natural Resources

E-Mail: elisabeth.quendler@boku.ac.at

Received: 28 November 2017; accepted: 1 March 2017; first published on May 2017 monotonous and repetitive work processes, additional equipment provides assistance during the milking work [5]. The higher the technical equipment of the milking parlour, the less the time required, and thus the physical workload [8]. In a milking parlour, upgradeable, shutdown and automatic cluster removal equipment is most frequently used as additional equipment providing assistance [9]. The heart rate and energy consumption can provide partial information about the work strain [4].

The Movisens ECG and activity sensor is a measuring device designed for the research approach which determines not only the heart rate and energy expenditure, but also the heart rate variability, steps and activity category. Through the simple and practical handling as well as the mobile ECG long-term monitoring, the heart rate can be recorded for up to 2 weeks. Movement information is recorded on a multiaxis acceleration sensor and a temperature compensating barometric altimeter [10]. Using this data and the manual input of height, weight and age, the physical activity and energy expenditure can be estimated.

Luder et al. (1986) [11] compared the workload during milking with bucket milking, pipeline milking and the milking parlour. They recorded the heart rate, which was measured with 2 attached sensors. While working with 2 bucket milkers, the female and male milkers had a pulse rate that was $10 \%$ higher, on average, than during milking with 3 milking units in a pipeline milking system. It could not be proved that milking in the milking parlour is less burdensome than milking in the pipeline system. The heart rate of 3 female and 3 male Finnish milkers was studied during 
milking (on average $115 \mathrm{~min}$ ) by using the polar electro, and was 95 bpm. Additionally, Luder (1986) [11] investigated the energy expenditure to determine the physical strain (EN ISO 8996:2004) during milking in the herring bone milking parlour $2 \times 3$, which amounted to $8.8 \mathrm{WkJ} / \mathrm{MPmin}$, on average, and was less than the energy expenditure of milking work in a bucket and a pipeline milking system.

Previous studies focused on musculoskeletal disorders during milking in current milking systems; however, little is known about the effects of different milking systems and the equipment of modern milking parlours on milkers' physical strain [5]. Ahonen et al. (1990) [12] refer to the need for research showing the level of physical strain through more recent milking systems. In Finland, NevalaPuranen et al. (1996) investigated the physical workload in the milking parlour on the basis of oxygen consumption, heart rate and muscle activity. Recent studies on the oxygen consumption during milking in different milking systems are not available. Previous studies generally lack genderspecific representations of oxygen consumption, heart rate and energy consumption during milking work.

\section{OBJECTIVE}

Therefore, the aim of this study was to determine and evaluate the physical strain throughout the milking process and the different work subprocesses, based on the parameters: oxygen consumption $\left(\mathrm{VO}_{2}\right)$, heart rate $(\mathrm{HR})$ and energy expenditure (WkJ,Watt) of female and male milkers $(n=8)$. The results are presented descriptively and analytically according to gender, and compared with data in the literature. Measurement of oxygen consumption with the spirometer (Metamax3B, Cortex, Germany) was used as a valid reference for determination of energy expenditure and individual workload.

\section{MATERIALS AND METHODS}

The survey was conducted with 8 milkers on 4 Upper Austrian dairy farms in March 2015. The farms were equipped with the most common types of milking parlours in Austria: a herringbone swing-over or a side-by-side milking parlour. The average age of the milkers was 50 years $(\mathrm{SD}=2.4)(\mathrm{n}=8)$ and the body mass index $-24.4 \mathrm{~kg} / \mathrm{m}^{2}(\mathrm{SD}=3.5)(\mathrm{n}=8)$. The subjects milked in milking parlour types $2 \times 4$ swingover herringbone $(\mathrm{hb})(\mathrm{n}=4)$ and $1 \times 4$ side-by-side $(\mathrm{n}=2)$ or $2 \times 4$ side-by-side $(n=2)$. The milking parlour, milking pit and milking units were cleaned with a high pressure cleaner $(n=2)$ or a water hose with a spray nozzle $(n=2)$. During data collection, medium temperatures and relative humidity levels of $10.5^{\circ} \mathrm{C}$ and $69.2 \%(n=8)$ were measured in the milking parlour. For determining the working time requirements, the causal method according to Auerhammer (1979) was applied. The overall work and individual work processes during milking were divided into work subtasks and elements. The daily milking included preparatory work in and outside the milking pit (preparation of the milk tank, placing a milk filter, preparing milking units, driving cows into the waiting area, turning on the vacuum pump, etc.), the milking process in the milking pit (cleaning udders, fore milking, attaching/controlling/taking-off milking units), and follow-up work in and outside the milking pit (turning-off the vacuum pump, removing the milk filter, follow-up work on milking units, cleaning the milking parlour, follow-up work on the milk tank, etc.). Validation of the accuracy of the ECG and activity sensor of the Movisens company during milking was performed using the portable spirometer Metamax3B of the Cortex Biophysics company in Leipzig, Germany. In the professional performance diagnostics, it is used to determine oxygen consumption, $\mathrm{CO}_{2}$ emission and the respiratory minute volume, particularly for accurate determination of energy expenditure (in accordance with standard specifications, DIN EN ISO 8996: 2004). The technical failure of this unit is less than $2 \%$ [13]. The handy and user-friendly psychophysiological ambulatory Movisens measurement system optimizes research applications and records, a single channel ECG via dry electrodes built in a chest strap without disturbing the subject [14].

The physical strain throughout the milking and divided into each work subprocess was based on the oxygen consumption $\left(\mathrm{VO}_{2}\right)$, heart rate $(\mathrm{HR})$ and metabolic rate. Oxygen consumption was measured in $1 / \mathrm{h}, \mathrm{ml} / \mathrm{min} / \mathrm{kg}$ and in \% of $\mathrm{VO}_{2 \max }$ (MetaMax3B, Cortex Biophysics, Leipzig), HR in bpm (Movisens ECG and activity sensor, Karlsruhe) and metabolic rate in WkJ, Watt (Metamax3B and Movisens ECG and activity sensor). The metrological determination of oxygen consumption $\left(\mathrm{VO}_{2}\right.$ ) (in $\mathrm{l} / \mathrm{h}, \mathrm{ml} / \mathrm{min} / \mathrm{kg}$ and in $\%$ of $\mathrm{VO}_{2 \max }$ ) was performed with the spirometer Metamax3B for calculating energy consumption and measuring heart rate (HR) in bpm, and for validating the work energy expenditure (WkJ, watt) with the Movisens ECG and activity sensor for determining the physical strain throughout the milking process and follow-up work. To determine the energy expenditure and individual workloads, the measurement of oxygen consumption was used as a valid reference.

To measure the maximum oxygen uptake $\left(\mathrm{VO}_{2 \max }=35 \pm 7.4\right.$ $\mathrm{ml} / \mathrm{min} / \mathrm{kg})(\mathrm{n}=8)$, the maximum power $\left(\mathrm{P}_{\max }^{2 \max }=2.7 \pm 0.4\right.$ $\left.\mathrm{W} \mathrm{kg}{ }^{-1}\right)(\mathrm{n}=8)$, maximum heart rate $\left(\mathrm{HR}_{\max }=175 \pm 6.1 \mathrm{bpm}\right)$ $(\mathrm{n}=8)$ and individual strain on the milker, a stress test on the bicycle ergometer (Daum 8008 TRS, Fürth, Germany) was performed. After a 3-minute standardized warm-up at 40 watts, each minute was increased by 20 watts until the subjects were not able to maintain a required cadence of at least 70 revolutions per minute.

The data were analyzed descriptively with a spreadsheet programme (Microsoft Excel 2007). To verify possible existing differences between the genders and between the instruments, the t-test and Wilcoxon test were used on independent samples. The level of significance was set at $\mathrm{p} \leq 0.05$.

\section{RESULTS}

Preparatory work. Prior to the actual milking operations, preparatory work was performed outside the milking pit, including preparing the milk tank, which consisted in the removal of residual water from the milk line and changing the lance from the flushing apparatus to the milk tank, preparation of interim disinfection, preparation of peracetic acid in a bucket for disinfecting the teat cups, and rounding-up the cows in the waiting area. The work processes in the milking pit included inserting the milk filter, preparing the milk cutter for milking, spraying the milking 
parlour floor, preparing the strip cup, taking milking units from the rinsing cup, opening doors, and turning on the vacuum pump. During the preparatory work, which lasted an average of 7 Man power minutes (MPmin), the average oxygen consumption of the subjects $(\mathrm{n}=8)$ was $56.6 \pm 12.3 \mathrm{l} / \mathrm{h}$, which is below the aerobic threshold of $60 \mathrm{l} / \mathrm{h}$ of physical work, according to UNI EN ISO standard 8996. Oxygen consumption in liters per WPh was significantly higher in the women than in the men, and was about $5.1 \mathrm{l} / \mathrm{h}$ above the aerobic threshold $(\mathrm{p}=0.0353)$. Oxygen consumption, calculated by means of the energy metabolism, was an average of 174 watt $/ \mathrm{m}^{2}$ during the preparatory work $(\mathrm{n}=8)$ (calculated with Metamax3B), which corresponds to an average energy expenditure. The male milkers had a work energy expenditure that was $4.2 \mathrm{WkJ} / \mathrm{MPmin}$ higher than that of the female milkers $(\mathrm{p}=0.0784)$. The average heart rate $(\mathrm{n}=8)$ was below the physiological endurance limit of $110 \mathrm{bpm}$ [15]. The gender-specific difference in energy consumption was $4.2 \mathrm{WkJ} / \mathrm{MPmin}$.

Milking. With the completion of the preparatory work and the cows entering the milking parlour, the milking process began in the milking pit. This included udder cleaning, premilking, putting on the milking units, aligning, monitoring, mechanically post-milking by pressing down the milking units, and taking off the milking units. After all cows had been milked and the teats dipped, the cows were released through a pneumatic frontal release or by mechanically opening the parlour exit.

The milking process took an average of 64 minutes and a related oxygen consumption $(43.5 \pm 9.41 / h)(n=8)$ below the aerobic threshold. The men, compared to the women, had a $14.8 \mathrm{l} / \mathrm{h}$ higher oxygen consumption $(\mathrm{p}=0.0089)$. The average heart rate $(n=8)$ was below the limit of exertion during the milking process. The milking process proved to have an average AEE, at $134 \mathrm{w} / \mathrm{m}^{2}(\mathrm{n}=8)$. During the milking process in the milking pit, the male milkers showed with $3.4 \mathrm{WkJ} / \mathrm{MP}_{\min }$ a significantly higher total energy expenditure than the female milkers $(\mathrm{p}=0.0371)$.

Follow-up work. After milking, cleaning and flushing work processes were carried out in the milking parlour. These included turning-off the vacuum pump, removing the milk filter, preparing filtration equipment for rinsing, placing the milking units in the rinsing cup, and emptying the milk collecting vessel, initiated by pressing a button. The milking parlour, milking pit and milking units were cleaned with a high pressure cleaner or water hose with a spray nozzle. The average oxygen consumption $(5.6 \pm 13.3 \mathrm{l} / \mathrm{h})$ of the female milkers $(n=8)$ during the follow-up work, on average, was $15 \mathrm{MPmin}$, which was below the aerobic threshold. The men exceeded the limit with $7.5 \mathrm{l} / \mathrm{h}$, and differed significantly from the women's average oxygen consumption $(\mathrm{p}=0.0002)$. The activity energy expenditure, derived from oxygen consumption, amounted to an average of $169 \mathrm{w} / \mathrm{m}^{2}$ during the follow-up work $(\mathrm{n}=8)$, and can also be considered an average energy expenditure. In the average energy expenditure, there were significant differences between the male and female milkers $(p=0.0007)$. The average heart rate $(n=8)$ remained below the working physiological endurance limit. The average oxygen consumption, energy expenditure and heart rates were very similar to the preparatory work because of similar activities and body movements.
Milking process. On the farms investigated, the milking process took an average of $86 \mathrm{MPmin}$. The average oxygen consumption $(46.5 \pm 9.9 \mathrm{l} / \mathrm{h})$ of the male and female milkers $(n=8)$ was below the aerobic threshold. The calculated oxygen consumption in $\mathrm{ml} / \mathrm{min} / \mathrm{kg}$, compared to the maximum oxygen consumption, corresponds to a moderate strain. The absolute oxygen consumption in $1 /$ h showed significant differences between male and female milkers ( $\mathrm{p}=0.0048)$. Among the men, the average oxygen intake was $16.3 \mathrm{l} / \mathrm{h}$ higher than among the women. With $134 \mathrm{Watt} / \mathrm{m}^{2}(\mathrm{n}=8)$, the milking process corresponded to an average energy expenditure. During the milking process in the milking pit, the male milker had a $3.4 \mathrm{~kJ} / \mathrm{MPmin}$ higher energy expenditure than the female milkers $(\mathrm{p}=0.0371)$ (Tab. 1.)

Table 1. Average oxygen intake in $\mathrm{ml} / \mathrm{min} / \mathrm{kg}$ and in $\%$ of $\mathrm{VO}_{2 \max }$, heart rate in bpm and medium activity energy expenditure (AEE) in WkJ/MPmin with standard deviations during the milkers' $(n=8)$ milking process and divided by gender

\begin{tabular}{|c|c|c|c|c|c|}
\hline Milking process & $\begin{array}{c}\mathrm{VO}_{2} \\
\mathrm{ml} / \mathrm{min} / \mathrm{kg}\end{array}$ & $\begin{array}{c}\mathrm{VO}_{2} \% \\
\text { of } \mathrm{VO}_{2 \max }\end{array}$ & $\begin{array}{l}\mathrm{HR}^{1)} \\
\mathrm{bpm}\end{array}$ & $\begin{array}{c}\mathrm{AEE}^{1)} \mathrm{WkJ} / \\
\mathrm{MPmin}\end{array}$ & $\begin{array}{c}\mathrm{AEE}^{2)} \\
\text { WkJ/MPmin }\end{array}$ \\
\hline Milkers $(n=8)$ & $11.0 \pm 0.9^{\mathrm{a}}$ & $32.4 \pm 7.9^{\mathrm{a}}$ & $97 \pm 16.5^{a}$ & $2.1 \pm 0.5^{b}$ & $11.3 \pm 2.6^{c}$ \\
\hline ale milkers $(n=4)$ & $10.7 \pm 1.0$ & $27.8 \pm 4.1$ & $88 \pm 4.6$ & $2.5 \pm 0.3$ & $13.2 \pm 1.9$ \\
\hline $\begin{array}{l}\mathrm{n}=4 \text { ) } \\
\text { emale milkers }\end{array}$ & $11.3 \pm 0.9$ & $37.0 \pm$ & $105 \pm 20.8$ & $1.7 \pm 0.3$ & 03 \\
\hline
\end{tabular}

1)Data collected with Movisens ECG and activity sensor

${ }^{21}$ Data collected with Metamax3B

${ }^{a}$ - not significant; ${ }^{b}$ - significant; ${ }^{c}$ - highly significant

The average heart rates $(\mathrm{n}=8)$ during the milking process were always below $110 \mathrm{bpm}$. The $\mathrm{MPkJ} / \mathrm{MPmin}$ measured with the spirometer's energy expenditure data (Metamax3B) were, on average, $419 \%$ higher than those measured with the Movisens EEG and activity sensor, which used algorithms on the basis of acceleration data to calculate the results.

\section{CONCLUSION}

During the preparatory and follow-up work, the activities were carried out by walking in different rooms, which caused a higher metabolic rate (WkJ/MPmin) (determined with Metamax3B), a higher oxygen consumption and a higher heart rate. The intensity and the number of muscles used through monotonous and constantly repetitive hand and arm movements while mostly standing, but with some slow walking when changing the milking parlour side, are crucial to the energy consumption. A strain in this sense also leads to oxygen consumption, which subjectively expresses itself in increased breathing and a raised heart rate $[16,17]$. The higher energy expenditure (determined with Metamax3B) of men compared to women in all work subtasks can be explained by the fact that men generally have more muscle mass and a higher energy expenditure at rest and during exercise [18].

The gender-specific difference in the relative oxygen consumption (Tab. 1) was due to the lower pulmonary function parameters, such as lower respiratory rate, lower tidal volumes, lower respiratory threshold and the lower respiratory minute volume of women. The significant major differences in absolute oxygen consumption $(1 / h)$ in men and women in all work processes can be explained by size and weight. The men, on average, were $29 \mathrm{~kg}$ heavier and $10 \mathrm{~cm}$ taller than the female milkers. 
The higher heart rate of the female milkers during the same work was probably caused by the average lower cardiac output of the women (500-600 $\mathrm{ml})$, compared to the men (600-800 ml), which causes a smaller stroke volume (55\%). This means that the oxygen demand of women is covered by an increased heart rate during the same physical activity $[19,20]$. In the entire milking process and in all subtasks, the workload $\left(\mathrm{VO}_{2}\right.$ in $\%$ of $\left.\mathrm{VO}_{2 \max }\right)$ among women was higher than among men. According to Nevala-Puranen et al. (1996) [21], a relative oxygen uptake (in $\%$ of $\mathrm{VO}_{2 \max }$ ) during milking was determined by $21 \%(n=6)$. In the presented study, an average load of $32.4 \%$ during the entire milking process (86 WPmin) $(n=8)$ was found. During the milking process, the endurance limits that exist for $\mathrm{HF}, \mathrm{VO}_{2}$ and work energy expenditure were not exceeded, on average. According to Nevala-Puranen et al. (1996), the oxygen consumption was $0.6 \mathrm{l} / \mathrm{min}$ during milking (18 MPmin). In this study, it was $0.78 \mathrm{l} / \mathrm{min}$ for the entire milking process. According to Nevala-Puranen et al. (1996), the endurance limit was also not exceeded during the milking process (115 MPmin). The heart rate determined in this study during the entire milking process was almost identical with that of the Finnish investigation. The energy expenditure, determined by Luder et al. (1986), was $8.8 \mathrm{WkJ} / \mathrm{MPmin}$ during the milking. By dividing the milking process into different activities, preparatory work, milking and follow-up work, and by differentiating between the arithmetic means for these activities, overruns in the endurance limit were observed during the preparatory and follow-up work (Fig. 1).

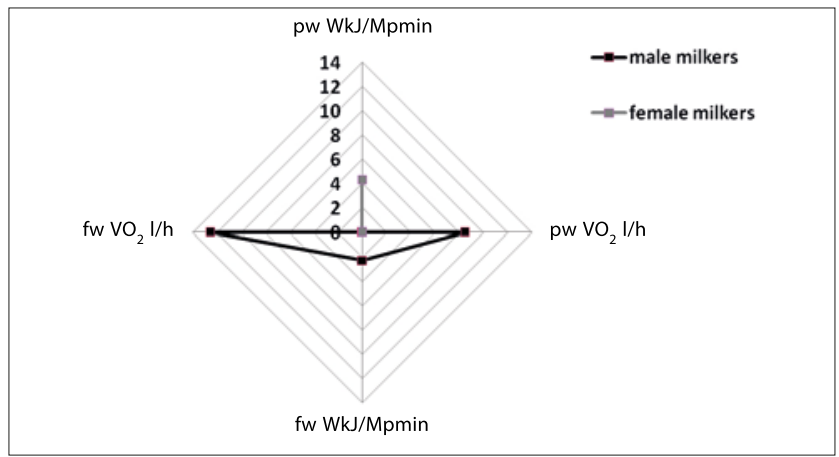

Figure 1. Deviation in $\%$ from the limit value $\left(\mathrm{VO}_{2}=60 \mathrm{l} / \mathrm{h}, \mathrm{WkJ} / \mathrm{MPmin}=17\right.$ in men and 12 in women) based on the endurance limit, the activity energy expenditure per minute (calculated with Metamax3B), and oxygen consumption in I/h divided by work subprocess and gender.

pw - preparatory work; fw - follow-up work

During the preparatory work, women exceeded the endurance limit (12 WKJ/MPmin) by $0.5 \mathrm{WkJ} / \mathrm{MPmin}$. Men exceeded the limit of exertion (17WkJ/MPmin) by $0.4 \mathrm{WkJ} / \mathrm{MPmin}$ during follow-up work. The limit of exertion $(60 \mathrm{l} / \mathrm{h})$ was topped during preparatory $(65.1 \mathrm{l} / \mathrm{h})$ as well as follow-up work by male milkers, according to UNI EN ISO standard 8996. Regarding HR, the bpm of 110 was not exceeded during any of the work steps. This means that milking causes a moderate strain and the entire milking process can be exercised during a working day of 8 hours without increasing muscular fatigue. The workload during preparatory and follow-up work should be reduced through sharing work by using technical aids (cowboy), taking additional breaks, or working at a slower working pace. With the gender-specific evaluation, it was found that the physical strain in female milkers was higher than in men during the milking process.

In contrast to the MM3B spirometer, the simple and practical operation of the Movisens ECG and activity sensor and evaluation software were appreciated. Evaluation of the results by means of the software was straightforward. Between the measuring instruments, there were huge discrepancies in the results (419\% compared to MM3B), which makes the activity sensor inadequate for measuring energy consumption. The use of different prediction models for AEE, depending on the type of activity, improves AEE estimates. Generally, the sensor tends to underestimate energy consumption, this was also found by Birte von Haaren et al. (2011) [24]. Overall, the Movisens kmsMove sensor proved to be an ideal instrument for the identification and analysis of everyday movements in rehabilitation patients; However, if this instrument should be suitable for the determination of the actual work energy expenditure of manual labor, it must be examined more intensively in further studies.

\section{REFERENCES}

1. Wolkerdorfer F. Automatisches Melken in Oberösterreich - Erfahrungen und Empfehlungen aus und für die Praxis. Viehwirtschaftliche Fachtagung. 2012 April 25-26; Raumberg-Gumpenstein, Austria. Raumberg-Gumpenstein: Lehr- und Forschungszentrum für Landwirtschaft; 2012.

2. Statistik Austria und Agrarmarkt Austria. Kuhmilcherzeugung und -verwendung. Statistik Austria und Agrarmarkt Austria, 2015.

3. Schön H, Auernhammer H, Bauer R, Boxberger J, Demmel M, Estler M et al. Landtechnik Bauwesen, Verfahrenstechnik - Arbeit - Gebäude - Umwelt. BLV Verlagsgesellschaft, München, 1998.

4. Auernhammer H. Methodische Möglichkeiten und Grenzen der Bewertung und Beurteilung der Arbeitsbelastung. Bayerisches Landwirtschaftliches Jahrbuch, 1989.

5. Hoehne-Hückstädt U, Kauke M. Arbeitsbelastung beim Melken. ARTSchriftreihe, 2009.

6. Jakob M, Rose S, Brunsch R. Einfluss Melkstandausstattung auf die Arbeitsbelastung des Melkers. Zeitschrift für Arbeitswissenschaften. 2007; 3(61): 173-181.

7. Reinemann DJ. A Review of Studies on the Ergonomics of Milking. University of Wisconsin Milking Research and Instruction Lab, 2005.

8. Schick M. Vor- und Nachteile verschiedener Melkverfahren aus der Sicht der Arbeitswirtschaft. Forschungsanstalt Agroscope, ReckenholzTänikon, ART-Schriftreihe. 2009; 9: 49-58.

9. ÖKL-Arbeitskreis Landwirtschaftsbau. Melkstandanlagen. ÖKL-Merkblatt Bauen. 2012; 2(51): 7-14

10. Kirst M. Verbesserung der automatischen EKG-Analyse durch Hinzunahme von Kontextinformationen. Dissertation. Karlsruher KIT, 2013.

11. Luder W, Huber R, Juliszewski T. Arbeitsbelastung beim Melken. FATBerichte. Tänikon. 1986; 303: 2-5.

12. Ahonen E, Venäläinen JM, Könönen U, Klen T. The physical strain of dairy farming. Ergonomics. 1990; 33(12): 1549-1555.

13. Macfarlane DJ, Wong P. Validity, reliability and stability of the portable Cortex Metamax 3B gas analysis system. University of Hong Kong. 2011; 25-39.

14. Movisens GmbH. Products. http://www.movisens.com/de/produkte/ ekg-und-aktivitaetssensor. (access: 2015.4.8).

15. Hartmann B, Spallek M, Ellegast R. Arbeitsbezogene Muskel- und Skeletterkrankungen. Ecomed, 2013.

16. Biesalski H, Grimm P, Nowitzki-Grimm S. Taschenatlas Ernährung. 6th ed. Stuttgart, Thieme Verlag KG, 2015.

17. Dallmann S. Sportmedizin. http://www.sportmedizin-dallmann.de/ praxisspektrum/sportmedizin. (access: 2015.7.22).

18. Weineck J. Sportbiologie. 9th ed. Spitta Verlag \& Co. KG. Germany, 2004.

19. Reichelt A. Komplementärmedizin - Kompendium. https://books. google. at/books?id=jfwSBsKgrycC\&pg=PA436\&dq=andreas+reich elt+komplement\%C3\%A4rmedizin+buch\&hl=de\&sa=X\&ved=0C 
DoQuwUwAGoVChMIs5WI5qLuxgIVCdYUCh1YFQOk\#v=onep age \&q=andreas\%20reichelt\%20komplement\%C3\%A4rmedizin\%20 buch\&f=false. (access: 2015.7.22)

20. Spomedial. Die maximale Sauerstoffaufnahme $\left(\mathrm{VO}_{2}\right)$. http://www. dshs-koeln.de/imb/spomedial/content/e866/e2442/e3862/e4009/e4019/ index_ger.html. (access: 2015.6.12).

21. Nevala-Puranen N, Kallionpää M, Ojanen K. Physical load and strain in parlor milking. International Journal of Industrial Ergonomics. 1996; 18: 277-282.

22. Anastasopoulou P, Tubic M, Schmidt S, Neumann R, Woll A, Härtel $S$, et al. Validation and comparison of two methods to assess human energy expenditure during free-living activities. In: Gabrys L, Thiel C, Tallner A, Wilms B, Müller C, Kahlert D, Jekauc D, Frick F, Schulz H, Sprengeler O, Hey S, Kobel S und Vogt L. Akzelerometrie zur
Erfassung körperlicher Aktivität-Empfehlungen zur Methodik. Sportwissenschaft. 2015;45(1). p. 1-9.

23. Preece SJ, Goulermas JY, Kenney LPJ, Howard D, Meijer K, Crompton R. Activity identification using body-mounted sensors-a review of classification techniques. In: Gabrys L, Thiel C, Tallner A, Wilms B, Müller C, Kahlert D, et al. Akzelerometrie zur Erfassung körperlicher Aktivität - Empfehlungen zur Methodik. Sportwissenschaft. 2015; 45(1). p.1-9.

24. Von Haaren B, Gnam J, Härtel S, Löffler S, Helmhold S, Anastasopoulou $\mathrm{P}$, et al. Energieumsatzmessung mit Aktivitätssensoren - Validität des kmsMove-Akzelerometers. In: Proceedings of the Jahrestagung der dvs-Kommission Gesundheit; 2011 Feb 16-17; Karlsruhe, Germany. Karlsruhe: 2011. 